\title{
The Papal front \\ Part 2: Seen through numerical weather prediction models
}

\author{
H. Volkert1, S. P. Ballard2 and M. G. Hutchinson² \\ 1 Institut für Physik der Atmosphäre, DLR-Oberpfaffenhofen, Weßling, Germany \\ ...2 Met. Office Unit, Joint Centre for Mesoscale Meteorology, University of Reading, UK
}

Eight years ago, on 3 May 1987, a squall-line type front ran along the northern rim of the Alps undergoing significant intensification. The event was named the 'Papal front' as it disrupted the helicopter flight which was meant to take the Pope from Munich to Augsburg. It has motivated several case-studies (e.g. Volkert et al. 1991; referred to as VWT in the following) and served as a kind of prototype for orographically influenced fronts (see the review article by Egger and Hoinka 1992). The Papal front was also selected as a case-study for the Summer School on "Orographic Processes in Meteorology", which took place at the Meteorological Office College in July 1993.

In Part 1 of this series of three articles John Sherwood gave the forecaster's perspective (Sherwood 1995). Here, we discuss to what extent current operational weather prediction models were able to capture the event. In Part 3 Volkert and Steinacker (this issue) will present a research-type analysis of the front.

We will compare model analyses and forecasts of equivalent potential temperature and the along-Alps westerly wind component, have a look at model-generated precipitation fields, inspect the impact of model resolution on the mesoscale structure of the pressure field, and see how well time-series at representative grid points reproduce the observations.

Numerical weather prediction (NWP) consists essentially of three components: (i) the blending of a short-range forecast from the past, the first guess, with the available current observations on to the net of model grid points - analysis; (ii) the balancing of analysed wind and temperature fields - initialisation; and (iii) the stepping forward in time of the initial fields by applying mathematical equations that represent all relevant physical processes - forecast. Analysis and initialisation are also referred to as data assimilation. Atkinson and Gadd (1986, pp. 118-125) give a thorough and well illustrated description of that process in their excellent book aimed at non-specialist readers. A high horizontal resolution between adjacent grid points is essential to resolve the mesoscale structures that are inherent both in frontal systems and in mountain ranges such as the Alps.

The models used here have a horizontal resolution of $90 \mathrm{~km}$ or better (see Table 1), but they were not available in 1987 . Therefore, this study exemplifies the results that can be expected from current NWP models for situations of strong frontogenesis near the Alps rather than reviewing the actual numerical forecast at the time of the event. We present analyses and short-range forecasts from the T213L 31 forecasting system of the European Centre for Medium-range Weather Forecasts (ECMWF), operational since 1991 (the name indicates 213 spectral modes in the horizontal and 31 levels in the vertical), and forecasts from the global model (GM), the limited area model (LAM) and the new mesoscale model (NMM) of the Meteorological Office. The latter are versions of the Meteorological Office's unified model, which has been in operational use since 1991 . At ECMWF a complete reassimilation was carried out starting as early as 29 April 1987 to obtain suitable analyses for forecast reruns and a picture of the actual state of the atmosphere at that time. Unlike during normal operations, when the unified model runs from its own data assimilation cycle, here the Meteorological 
Table 1 Some specifications of the models used in this study

\begin{tabular}{lcccc}
\hline Model & T213L31 & GM & LAM & NMM \\
\hline $\begin{array}{l}\text { Operating agency } \\
\text { Domain }\end{array}$ & $\begin{array}{c}\text { ECMWF } \\
\text { global }\end{array}$ & $\begin{array}{c}\text { MO } \\
\text { global }\end{array}$ & $\begin{array}{c}\text { MO } \\
\text { North Atlantic and } \\
\text { Europe }\end{array}$ & $\begin{array}{c}\text { MO } \\
\text { here: } \\
\text { central Europe } \\
\text { routinely: UK }\end{array}$ \\
$\begin{array}{l}\text { Effective grid size }(\mathrm{km}) \\
\text { Number of levels }\end{array}$ & 60 & 90 & 50 & 17 \\
\hline
\end{tabular}

See text for a full explanation of the table entries. MO $=$ Meteorological Office.
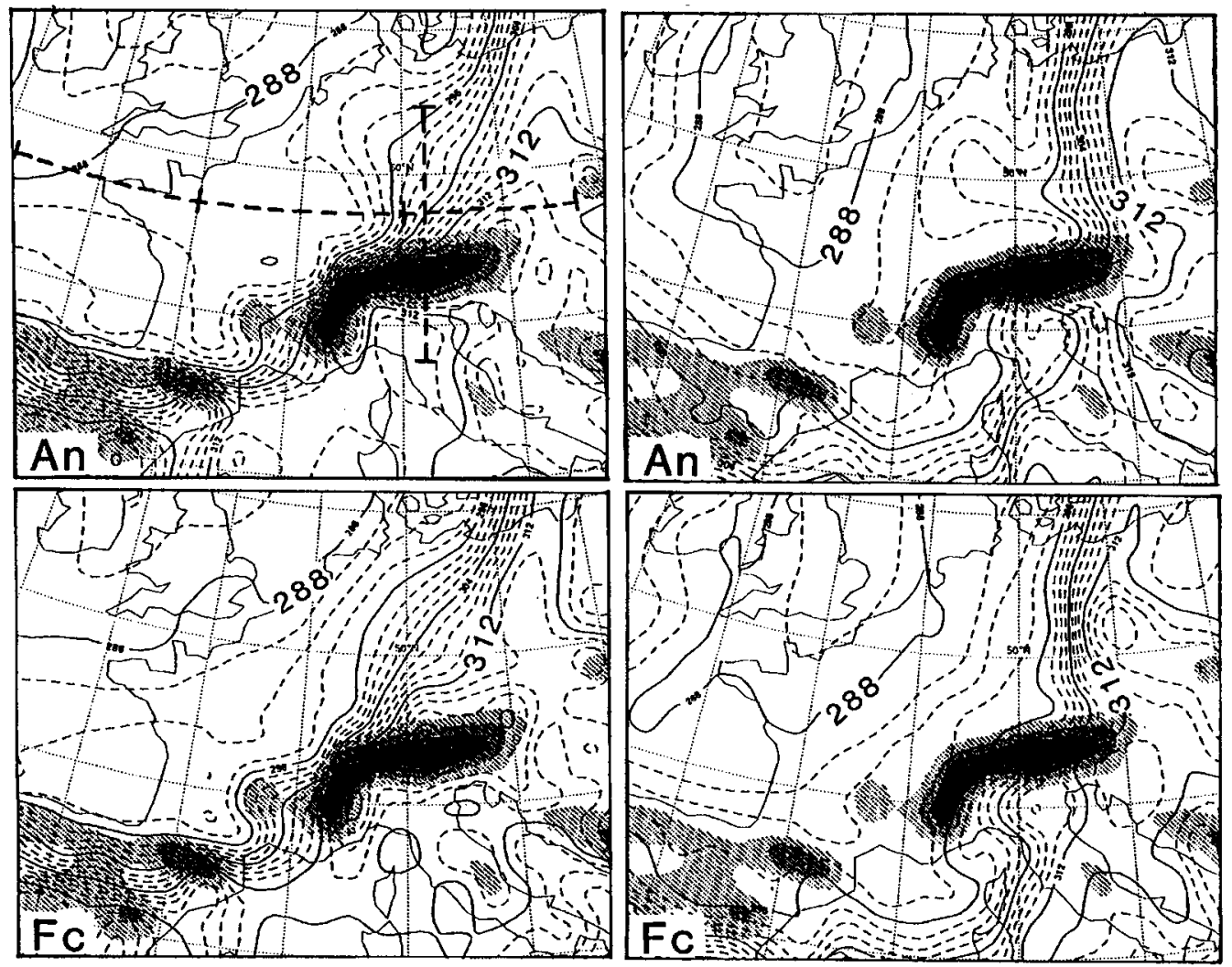

Fig. 1 Frontogenesis visualised by equivalent potential temperature at the $850 \mathrm{mbar}$ surface. Analyses (top) and one-day forecasts (bottom) from the ECMWF model for 1200GMT on 3 May 1987 (left) and 0000 GMT on 4 May 1987 (right). The positions of the cross-sections in Figs. 2 and 7 are displayed as dashed lines in the top left frame. The model orography above $1000 \mathrm{~m}$ is dotted with intensity increasing every $500 \mathrm{~m}$. Contour increment is $2 \mathrm{~K}$; only every fourth line is drawn fully to aid comparison.

Office reruns are based on the ECMWF reanalysis fields, specifically those of 2 May 1987 at $1200 \mathrm{GMT}$. More details about the models can be found in Simmons (1991, for T213L31) and in Cullen (1993, for the unified model).

\section{Frontogenesis along the Alps}

Surface observations compiled in VWT clearly indicated that the contrast across the Papal front intensified as the system rushed eastwards along the Alps, i.e. frontogenesis took place. Here, we use equivalent potential temperature $\left(\theta_{e}\right.$; see appendix) to identify frontal structures between more uniform adjacent airmasses.

ECMWF analyses and forecasts of $\theta_{\mathrm{e}}$ at the $850 \mathrm{mbar}$ pressure level (about $1.5 \mathrm{~km}$ above sea-level) are juxtaposed in Fig. 1. At 1200 GMT 
on 3 May 1987 a frontal band extended from the Baltic along the north-western rim of the Alps into Spain. It separated a potentially cool and dry airmass of $\theta_{e}<290 \mathrm{~K}$ over France from a warmer one $\left(\theta_{\mathrm{e}}>310 \mathrm{~K}\right)$ over eastern Europe.

During the following 12 hours one part of this frontal zone entered the Mediterranean between the Alps and the Pyrenees while another rushed along the northern flank of the Alps. In the latter region the contrast increased to $16 \mathrm{~K}$ across $3^{\circ}$ of longitude, equivalent to $7 \mathrm{~K}$ per $100 \mathrm{~km}$. At the rear side of the frontal zone the contours of $\theta_{\mathrm{e}}$ are bulged along the orography, which resembles the surface front analyses in VWT (their Fig. 3) and Sherwood (1995, his Fig. 8). All these features are well captured by the one-day forecast, which was initialised at 1200 GMT on 2 May.

The spatial contraction of the frontal zone within 12 hours is particularly evident in crosssections along $49^{\circ} \mathrm{N}$ (Fig. 2). The equivalent isentrope $\theta_{\mathrm{e}}=310 \mathrm{~K}$ at the leading edge hardly moved, whereas the lower values in its rear advanced significantly. Noteworthy is the huge dome of cool and dry air $\left(\theta_{\mathrm{e}}<295 \mathrm{~K}\right)$ with a vertical extent up to the 400 mbar pressure level behind the steep frontal zone. It is related to a lowered tropopause, which will be discussed in more detail by Volkert and Steinacker in Part 3 (this issue). The frontogenesis apparent in the analysed sections was correctly forecast, but it was not far enough advanced towards the east.

As the analyses shown are blended from a first-guess forecast and routinely obtained observations (see above), it is reassuring to note that such steep $\theta_{\mathrm{e}}$ frontal gradients have also been directly observed, e.g. south-west of the British Isles by the use of radiosondes dropped from the Meteorological Office research aircraft during the FRONTS 87 campaign (see Fig. 2 in Thorpe and Clough 1991).

\section{Precipitation}

A detailed survey of raingauge data led to the distinction of two partially overlapping precipitation regimes related to the Papal front to the north of the Alps (cf. Figs. 6 and 7 in VWT): moderate rainfall of about $10 \mathrm{~mm}$ in three hours was observed in the region north of the Danube, whereas fierce downpours with maximum intensity at the onset and totals up to
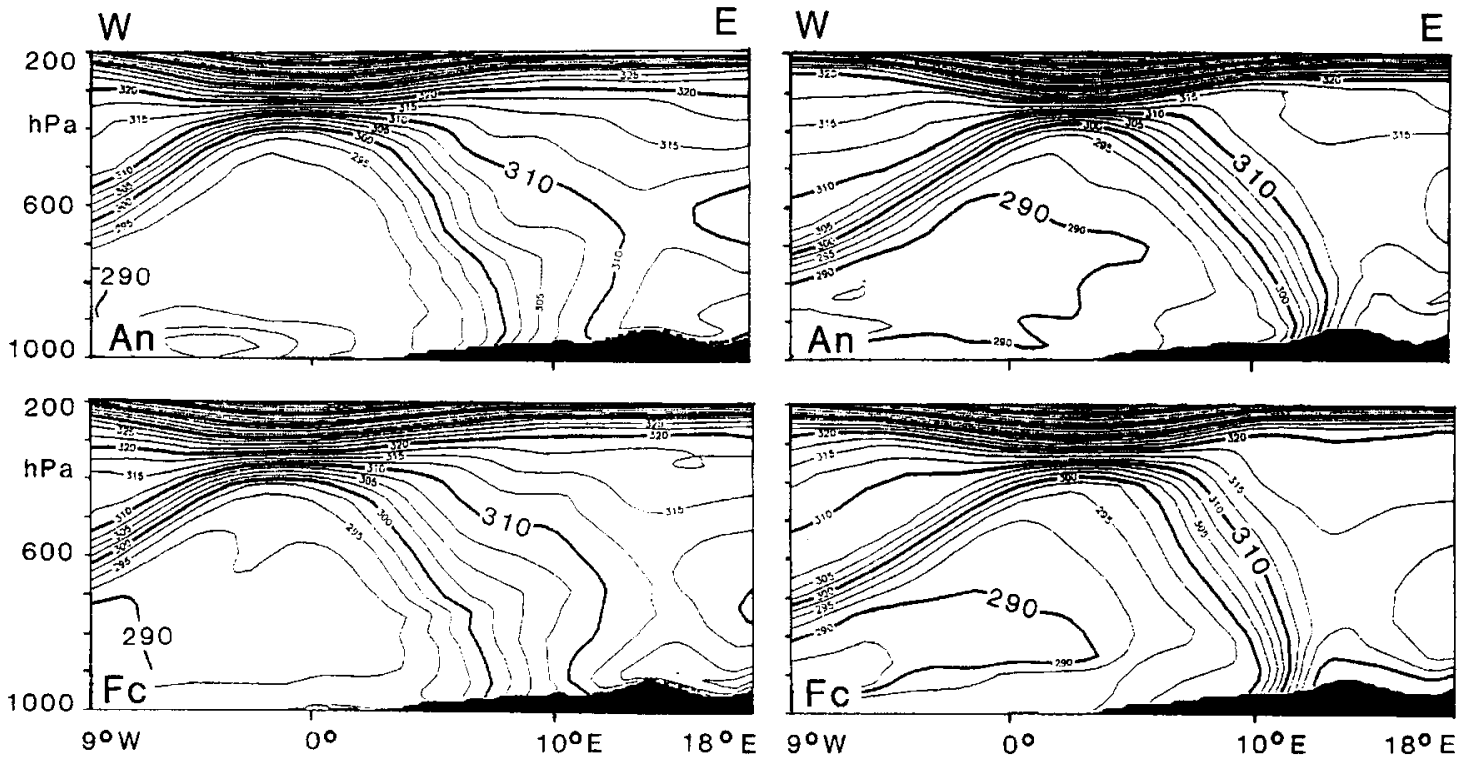

Fig. 2 Frontogenesis visualised by west-east cross-sections of equivalent potential temperature along $49^{\circ} N$. Analyses (top) and one-day forecasts (botwom) from the ECMWF model for 0600 GMT (left) and 1800 GMT (right) on 3 May 1987. The position of the cross-sections is given in Fig. 1. Contour increment is $2.5 \mathrm{~K}$; every fourh line is thickened to aid comparison. (1hPa $\mathbf{} 1 \mathrm{mbar}$.) 
$20 \mathrm{~mm}$ in three hours occurred to the south of it. To what extent was this captured by the model simulation?

Before looking at the model output we recall how precipitation is obtained, e.g. from the ECMWF model. The amount of water which falls out of higher levels into lower ones and eventually to the ground is related to the prognosed quantities, temperature and specific humidity, i.e. it is parametrized. Two categories are distinguished: large-scale and convective precipitation. The former is defined as an instantaneous adjustment that removes all moisture above 100 per cent relative humidity if supersaturation occurs for an entire cell of the computational grid. The latter is the end product of a more complicated cumulus cloud parametrization scheme, which modifies the vertical profiles of temperature and humidity, when certain criteria are met, in a way that mimics the observed behaviour of ensembles of cumulus clouds which do not always cover complete cells of the computational grid.

Both precipitation categories are stored as different variables and, thus, can be distinguished. The regions where three-hourly accumulations exceeded $5 \mathrm{~mm}$ are displayed in Fig. 3 for both categories and for two consecutive periods. An eastward-moving and expanding area of large-scale precipitation is preceded by areas of distinct convective rain along the flanks of the Alps. The local maxima are of the correct order of magnitude, whereas large-scale (convective) accumulations were simulated somewhat higher (lower) than observed.

\section{Impact of model resolution}

In order to investigate the impact of horizontal model resolution on forecasts of the Papal front, the Meteorological Office unified model was run at its three operational resolutions. The initial conditions were provided by fields extracted from the 1200GMT 2 May ECMWF reanalysis at $1.25^{\circ}$ latitude by $1.875^{\circ}$ longitude (approximately $140 \mathrm{~km}$ ) resolution on 14 pressure levels and interpolated on to the respective model grids and orographies. The GM forecast (roughly $90 \mathrm{~km}$ resolution) was used to provide boundary conditions for the LAM fore-

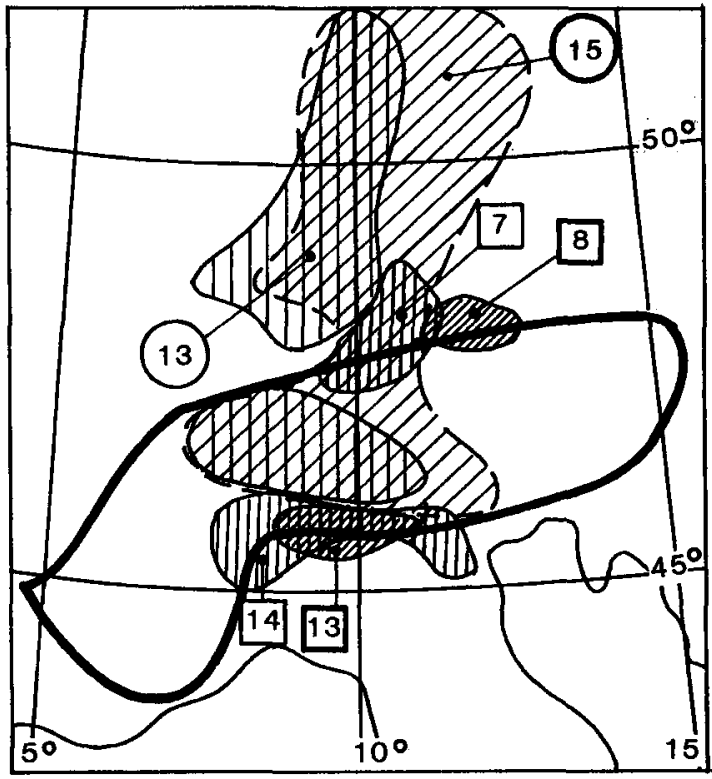

Fig. 3 Extent and propagation of modelled precipitation patterns along the Alps taken from the one-day forecast run of ECMWF. Shown are regions with three-hourly accumulations above $5 \mathrm{~mm}$ for large-scale (wide hatching) and convective (dense hatching) precipitation for the periods 1200-1500GMT (vertical hatching) and 1500 1800 GMT (diagonal hatching), together with local maxima (circles for large-scale, squares for convective precipitation; thin frames for 1200-1500 GMT, thick frames for 1500-1800GMT). The Alps are indicated by the $1000 \mathrm{~m}$ contour of the model orography (thick line).

cast $(50 \mathrm{~km})$ which in turn provided boundary conditions for the NMM forecast $(17 \mathrm{~km})$. The models normally take into account the mean orographic heights extracted at their respective resolutions. However, here two mesoscale forecasts were run, one using mean orographic heights extracted at the full resolution of the mesoscale model (HNMM) and the other using orography interpolated from the LAM (LNMM). The latter version thus has poorer resolution of the details of the Alpine massif and the ranges around it. These differences are exemplified in Fig. 4, where areas of model orography above $700 \mathrm{~m}$ are blackened. The GM sees the Alps as a wide block with some curvature in the western part and separated from a small Massif Central. The LAM experiences the Alps as a somewhat slimmer block, and also the Apennines, whereas secondary ranges such as Jura, Vosges, 

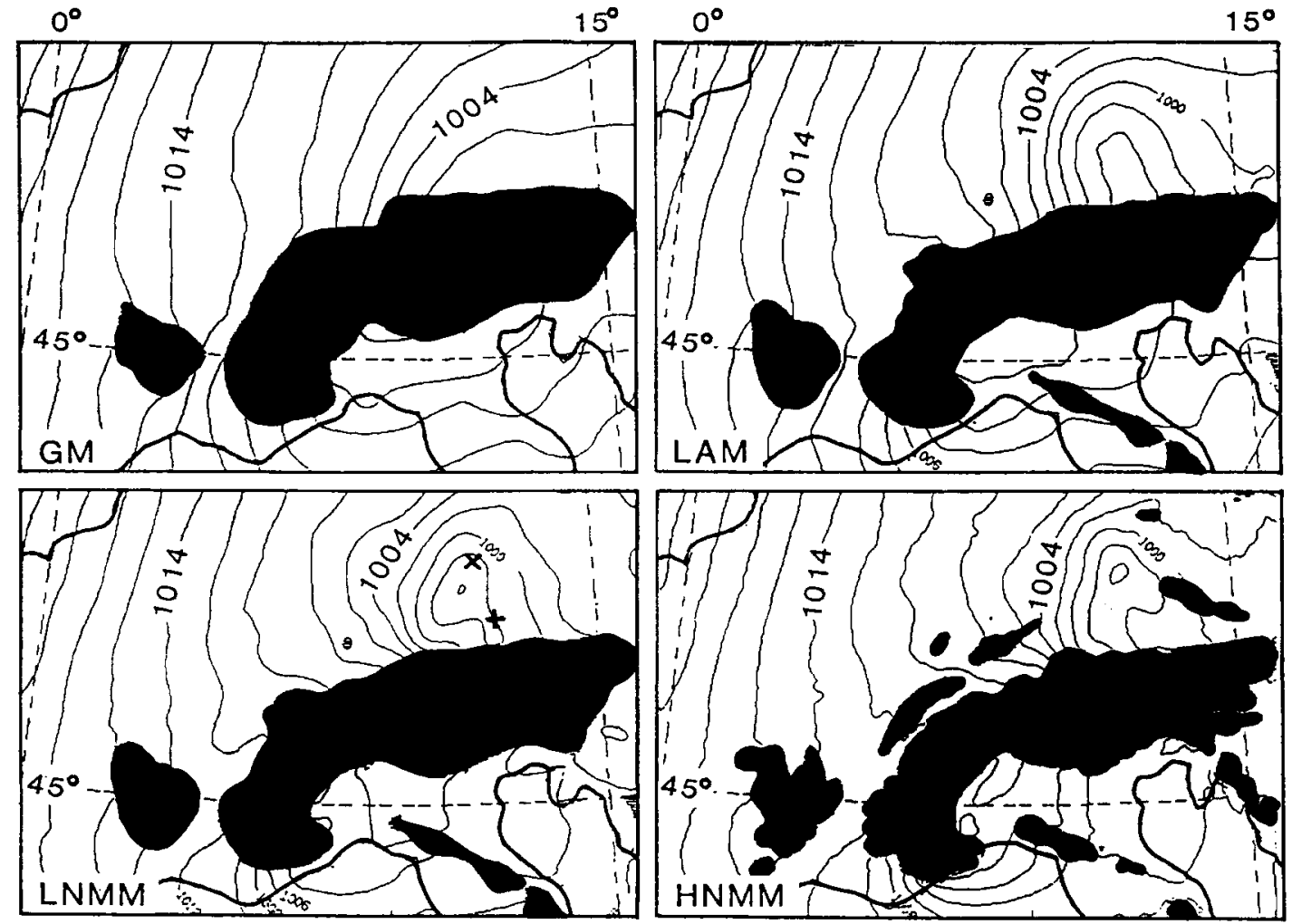

Fig. 4 30-hour forecast of mean sea-level pressure from the different components of the unified model, valid at $1800 \mathrm{GMT}$ on 3 May 1987: global model (GM) and limited area model (LAM), new mesoscale model with low-resolution (LNMM) and high-resolution (HNMM) orography. Positions of Munich (+) and Nuremberg (X) are indicated in frame LNMM.

Black Forest and Bavarian Woods only begin to show up in the full NMM orography. To resolve major inner Alpine valleys, however, one would need an even finer mesh size.

Mean sea-level pressure was chosen to demonstrate the impact of model resolution, because this quantity provides a sensitive indicator of the atmospheric mass field and the low-level flow. The observations showed (cf. Figs. 6, 7 and 8 in Sherwood 1995) that the Papal front intensified north of the Alps between a mesoscale low in the east and a mesoscale high pressure ridge building up over Switzerland in the west. The pressure gradient between Salzburg and Bregenz (Lake Constance) at $1500 \mathrm{GMT}$, for instance, amounted to 18 mbar over a distance of $250 \mathrm{~km}$. We note that this is equivalent to a geostrophic wind of some $70 \mathrm{~ms}^{-1}$, whereas the direction and speed of the observed wind (below $20 \mathrm{~ms}^{-1}$ ) was highly ageostrophic ${ }^{\star}$.

The 30-hour pressure forecast of the mentioned components of the unified model is presented in Fig. 4. It is evident that the fine mesh size is necessary to capture, at least to some extent, both the mesoscale low in the east and the pressure ridge over Switzerland in the west (LNMM and HNMM). The actual specification of the model orography (interpolated from the LAM or high-resolution dataset) proved to

\footnotetext{
* The approximated wind which results from the exact balance of the pressure gradient force and the Coriolis force (due to the Earth's rotation) is called the geostrophic wind. Observed winds, especially at the surface, often have a large ageostrophic (i.e. nongeostrophic) component due to other forces such as friction.
} 
be of minor importance in this dynamically driven case.

The absolute pressure values were about 4 mbar too low in the simulations, probably due to the non-standard initialisation procedure for our 'historic' case (see above). The forecast pressure gradient between Salzburg and Bregenz amounted to $12 \mathrm{mbar}$ as in the ECMWF analysis for $1800 \mathrm{GMT}$ on 3 May. The considerable difference compared to the observed peak gradient shows that very strong and shortlived mesoscale features are not always captured by the automated analyses which are partly based on a short-range forecast on the one hand and dominated by the quite coarse upper-air data on the other.

\section{Observed and forecast time-series}

The abruptness of the transition across the Papal front becomes especially evident through the inspection of time-series recorded at a location which was passed by the fully developed system. Wind, station-level pressure, and various temperatures from Garching ( $15 \mathrm{~km}$ north of Munich) are displayed in Fig. 5.
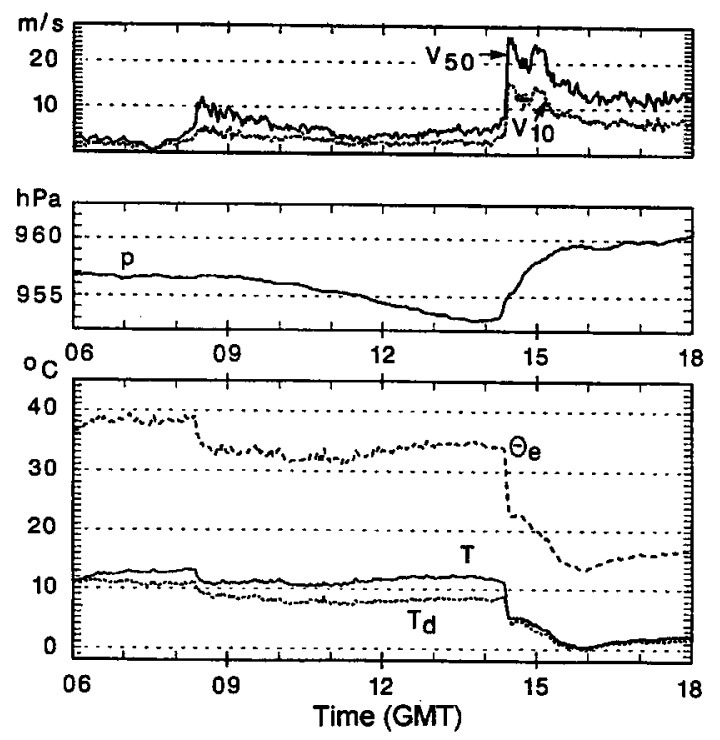

Fig. 5 Time-series of observations from Garching (near Munich) on 3 May 1987: wind speed $\times x m$ above ground $\left(\mathrm{V}_{\mathrm{xx}}\right)$; station-level pressure (p); equivalent potential $\left(\theta_{e}\right)$, dry-bulb $(\mathrm{T})$, and dew-point $\left(\mathrm{T}_{\mathrm{d}}\right)$ temperatures. (1hPa $\equiv 1$ mbar.) (Taken from Volkert et al. 1991.)
The passage of the Papal front at 1420 GMT was accompanied by very sudden variations (temperature drop of $6.2 \mathrm{~K}$; equivalent potential temperature decrease of $12 \mathrm{~K} ; 10 \mathrm{~m}$ wind increase of $12 \mathrm{~ms}^{-1}$; pressure jump of $1.8 \mathrm{mbar}$ ) within a period of 6 minutes and continued change for another two hours (cf. detailed discussion in VWT). To what extent was this simulated by the NMM component of the unified model and can an Alpine influence be inferred?

Analogous time-series from grid points near Munich (50 km off the Alpine baseline) and Nuremberg $(200 \mathrm{~km})$ are given in Fig. 6 for the LNMM simulation. For Munich the passage of a
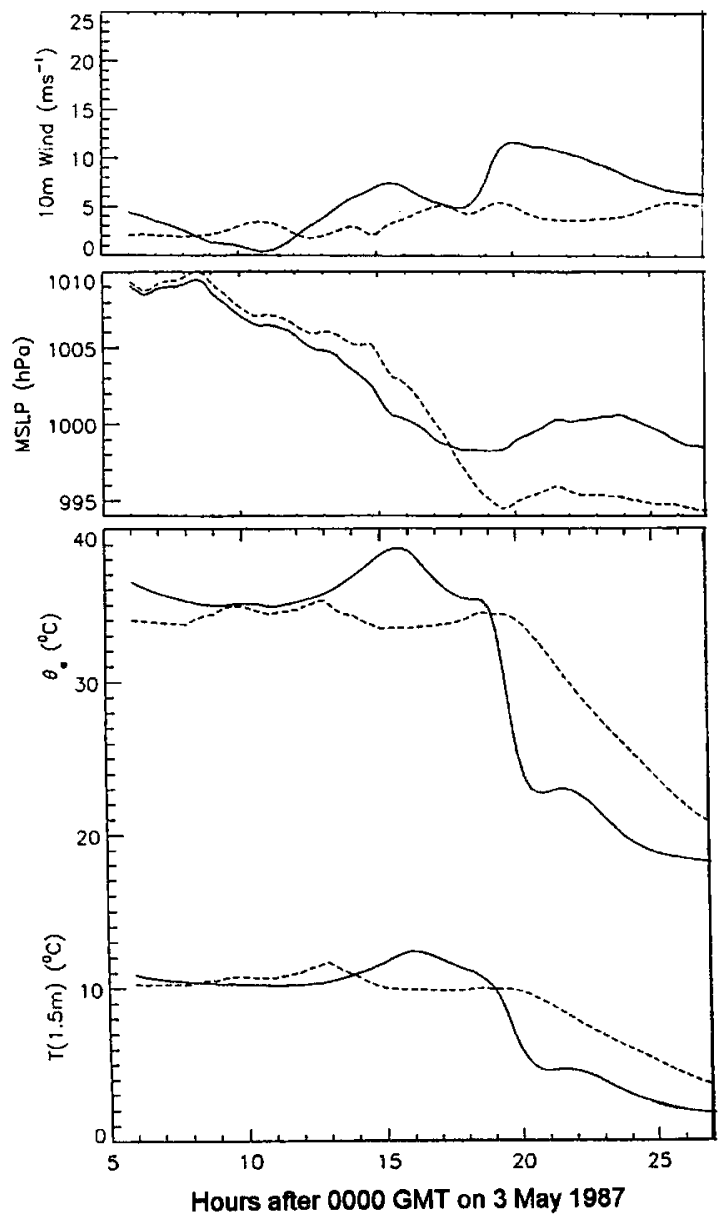

Fig. 6 Time-series of grid-point forecast by LNMM for Munich (full lines) and Nuremberg (dashed lines): wind speed at $10 \mathrm{~m}$; mean sea-level pressure; equivalent potential $\left(\theta_{e}\right)$, and dry-bulb $(\mathrm{T})$ temperatures at $1.5 \mathrm{~m}$. (1 hPa $\equiv 1$ mbar.) 
strong contrast in temperature (a fall of $5.5 \mathrm{~K}$ ) and in equivalent potential temperature (a fall of $12 \mathrm{~K}$ ) was simulated between 1900 and 2000 GMT, followed by a further decrease later on. Simultaneously, pressure and wind increased. In Nuremberg synchronous but less pronounced variations were simulated. For technical reasons time-series were only obtained for the LNMM run; the three-hourly values of HNMM, however, exhibit a time dependence similar to their LNMM counterparts.

In summary we note that the modelled front arrived in Munich about four hours late, that it was best marked in the temperature field although less pronounced than in reality, and that the contrast became smaller further away from the Alps.

\section{Orographic jet}

It is known from idealised simulations and laboratory experiments that a region of enhanced flow can evolve along blocking barriers. vWT identified such an 'orographic jet' along the Alps and behind the Papal front from the scarce post-frontal wind observations and numerical experimentation using a dry model. We now check whether a post-frontal orographic jet could be analysed and forecast with the complete NWP system of ECMWF in our case.

In Fig. 7 the model analysis and the 30-hour forecast of the zonal wind speed are juxtaposed in a section across the Alps (along $11^{\circ} \mathrm{E}$ ) for 1800 GMT. This is just behind the front as defined by $\theta_{\mathrm{e}}$ (see Fig. 2, left-hand panels). Both frames show a distinct maximum in the eastbound flow component of more than $10 \mathrm{~ms}^{-1}$ and clearly below the crest of the model Alps. As this is about $5 \mathrm{~ms}^{-1}$ faster and more closely attached to the orography than in the dry simulation of VwT (with similar spatial resolution; cf. their Fig. 13), we conclude that moist processes resulted in a strengthening of the orographic jet. Evaporation of rain and melting of snow is thought to have cooled the post-frontal air by several kelvins, which in turn strengthened the cross-frontal contrast and the propagation of the front (cf. Heimann 1990 for numerical experimentation

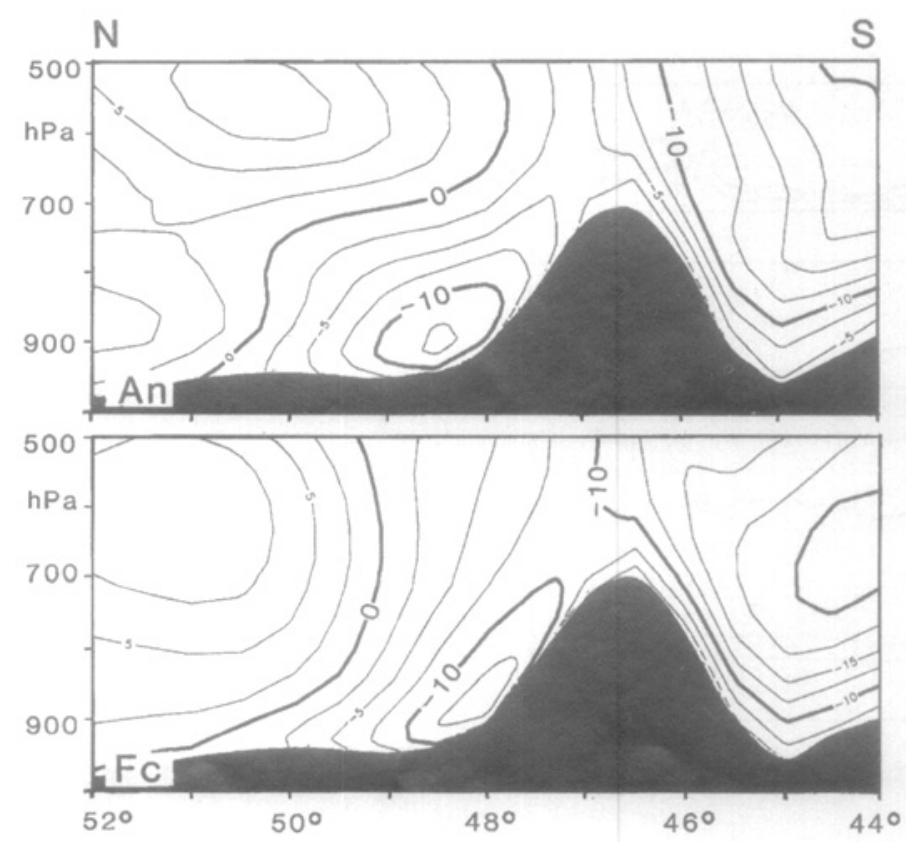

Fig. 7 Orographic jet along the northern flank of the Alps visualised by the zonal wind component in a north-south cross-section along $11^{\circ}$ E. Analysis (top) and 30-hour forecast (bottom) from the ECMWF model for 1800GMT on 3 May 1987. The position of the cross-sections is given in Fig. 1. Contour increment is $2.5 \mathrm{~m}^{-1}$; every fourth line is thickened to aid comparison. Negative values designate flow towards the east, i.e. into the section. (1 hPa $\square 1 \mathrm{mbar}$.) 
of such a situation with and without moist processes). The analysed and forecast velocity distribution of the orographic jet are in astonishing accord.

\section{Discussion}

In the preceding sections we have demonstrated to what extent two of the currently operational NWP systems were able to simulate the Papal front situation. This event has to be regarded as a difficult test case, as it was of only mesoscale extent - though triggered by synoptic-scale forcing - and as it involved a complicated interplay of moist processes within an orographically disturbed flow field.

As positive findings we recall: (i) frontogenesis in terms of equivalent potential temperature was well captured; (ii) the precipitation parametrization schemes distinguished between large-scale and convective rain similar to the observations and produced three-hourly sums of the correct order of magnitude; (iii) the temporal signal in grid-point time-series showed clearly a strong frontal contrast close to the Alps; (iv) the orographic jet as an indicator of the fast-moving front was well forecast; and (v) a truly mesoscale computational resolution is necessary to simulate the observed orographically disturbed mass and pressure fields.

On the other hand, a number of shortcomings have to be mentioned: (i) the simulated frontogenesis was slower and less pronounced than observed; (ii) even in the automated analysis the along-ridge maximum pressure gradient was not sufficiently captured; (iii) (and more generally) this brief study can at best give hints to the potential of current NWP systems for describing and forecasting severe weather near the Alps, but does not evaluate the model in a rigorous way.

The proven concept of the Meteorological Office Summer Schools with a strong emphasis on case-study work clearly stimulated our closer inspection of the model results. Because of the 'age' of the case the initialisation had to be more pragmatic than during normal operations.

Fast and active fronts along the northern flank of the Alps continue to pose severe fore- casting problems (see, for example, Kurz 1994 for a discussion of a similar event on 11 February 1991). Operational NWP systems are foreseen as playing an essential part within the coming Mesoscale Alpine Programme (see Binder and Schär 1995 for further information). It will place special emphasis on casestudy-type model evaluation (in addition to monthly statistics, say) and numerical experimentation (on/off switching of physical processes, control runs with cut-off Alps, i.e. the model orography is replaced by a plain from southern Germany right through to northern Italy) to infer the relative importance of the acting mechanisms.

\section{Acknowledgements}

This paper resulted from a fortunate European co-operation. The Papal front was selected as a case-study for the Summer School when the first author paid an extended visit to the Research Department of ECMWF. His hosts kindly integrated the case into the reanalyses program, which applies the new T213L31 model system to 'historic' situations. Gertraud Jacob (German Aerospace Research Establishment - DLR) competently finalised the figures. This assistance and the general support of ECMWF, the Meteorological Office, and DLR are gratefully acknowledged.

\section{Appendix: Explanation of potential and equivalent potential temperatures}

The potential temperature $(\theta)$ is the temperature which an air parcel would attain when brought adiabatically to the standard level of $1000 \mathrm{mbar}$. So, by definition, this derived quantity remains unchanged along adiabatic trajectories, whereas the ordinary temperature decreases with height.

The equivalent potential temperature $\left(\theta_{\mathrm{e}}\right)$ is a related derived quantity where the effect of latent heat release due to condensation is included. For dry air $\theta_{\mathrm{e}}$ equals $\theta$. Generally, $\theta_{\mathrm{e}}$ represents the temperature which a parcel of air would attain after being lifted dry-adiabatically to its condensation level, being further lifted moist-adiabatically until all the vapour has been transformed to cloud droplets (giving its 
latent heat to the air parcel), and after eventually being compressed adiabatically to the standard pressure of 1000 mbar. As this process cannot alter $\theta_{\mathrm{e}}$, although vertical motion and a water-phase conversion take place, it is conserved for airmasses undergoing purely dryand moist-adiabatic processes. Real airflows do not strictly meet this restriction when precipitation is formed and falls out. Nevertheless, $\theta_{\mathrm{e}}$ is well suited to distinguish between airmasses from different temperature and moisture regimes. Large horizontal gradients in $\theta_{\mathrm{e}}$ are good indicators of frontal zones. Formulae to compute $\theta$ and $\theta_{\mathrm{e}}$ can be found in standard textbooks (e.g. Wallace and Hobbs 1977, p. 69 and p. 79).

\section{References}

Atkinson, B. W. and Gadd, A. (1986) Weather - a modern guide to forecasting. Mitchell Beazley, London, $160 \mathrm{pp}$.

Binder, P. and Schär, C. (1995) (Eds.) Mesoscale Alpine Programme - Design Proposal. SMA Zürich, 63pp. (can be obtained from SMA, CH-8044 Zürich, Switzerland)
Cullen, M. J. P. (1993) The unified forecast/climate model. Meteorol. Mag., 122, pp. 81-94

Egger, J. and Hoinka, K.-P. (1992) Fronts and orography. Meteorol. Atmos. Phys., 48, pp. 3-36

Heimann, D. (1990) Three-dimensional modeling of synthetic cold fronts approaching the Alps. Meteorol. Atmos. Phys., 42, pp. 197-219

Kurz, M. (1994) Die Kaltfront vom 10.2.1991 - Betrachtungen zur Erscheinungsform und zur Vorhersage orographisch beeinflußter Fronten. Meteorol. Z., Neute Folge, 3, pp. 275-287

Sherwood, J. (1995) The Papal front. Part 1: A forecaster's perspective. Weather, 50, pp. 98-106

Simmons, A. (1991) Development of a high resolution, semi-Lagrangian version of the ECMWF forecast model. In: Proceedings ECMWF Seminar on Numerical Methods in Atmospheric Models, Vol. II, Reading, pp. 281-324

Thorpe, A. J. and Clough, S. A. (1991) Mesoscale dynamics of cold fronts: Structures described by dropsoundings in FroNTs 87. Q. F. R. Meteorol. Soc., 117, pp. 903-941

Volkert, H., Weickmann, L. and Tafferner, A. (1991) The Papal Front of 3 May 1987: A remarkable example of frontogenesis near the Alps. Q. $\mathcal{F} . R$. Meteorol. Soc., 117, pp. 125-150

Wallace, J. M. and Hobbs, P. V. (1977) Atmospheric science: an introductory survey. Academic Press, San Diego, xvii $+467 \mathrm{pp}$.

\title{
The Papal front Part 3: Findings from research-type analyses
}

\author{
Hans Volkert ${ }^{1}$ and Reinhold Steinacker ${ }^{2}$ \\ 1 Institut für Physik der Atmosphäre, DLR-Oberpfaffenhofen, Weßling, Germany \\ 2 Institut für Meteorologie und Geophysik, Universität Wien, Vienna, Austria
}

This is the third paper in a series of three that were written following case-study work at the Meteorological Office Summer School on "Orographic Processes in Meteorology" held in July 1993. In Part 1 John Sherwood gave the forecaster's perspective (Sherwood 1995); Part 2 discussed to what extent current operational weather prediction models were able to capture the event (Volkert et al. this issue). We now present some additional data analyses from a research-oriented point of view. Two questions are addressed: (i) how much is known about the synoptic-scale situation in which the Papal front developed? and (ii) how well can its threedimensional structure be inferred after it had developed? At the same time we relate the Papal front's synoptic-scale setting to that of the Great Storm of 1987 (discussed in some depth in this journal by, e.g., Hoskins and Berrisford 1988; HB from now on) and a well sampled Icelandic depression (Shapiro 1985). Furthermore, a comparison of manual and automated frontal analyses at upper levels indicates what could be gained operationally if better resolved upper-air data were available.

Potential vorticity (PV) is used as well as the 